\title{
Characterization of an Expanded IL-10-Producing-Suppressive T Cell Population Associated with Immune Tolerance
}

\author{
Yuya Yoshida, ${ }^{a}$ Norihisa Mikami, ${ }^{b}$ Yusuke Nakanishi, ${ }^{a}$ Maya Saimoto, ${ }^{a}$ Arata Nagaike,${ }^{a}$ \\ Haruka Shimono, ${ }^{a}$ Shohei Nakano, ${ }^{a}$ Takumi Tsuji, ${ }^{a}$ and Takeyuki Kohno*, \\ ${ }^{a}$ Department of Pathological Biochemistry, Faculty of Pharmaceutical Sciences, Setsunan University; 45-1 \\ Nagaotoge-cho, Hirakata, Osaka 573-0101, Japan: and ${ }^{b}$ Department of Experimental Immunology, Immunology \\ Frontier Research Center, Osaka University; 3-1 Yamadaoka, Suita, Osaka 565-0871, Japan. \\ Received December 9, 2019; accepted January 15, 2021; advance publication released online January 26, 2021
}

\begin{abstract}
An increase in the number of glucocorticoid-induced tumor necrosis factor receptor-family related gene/ protein (GITR) ${ }^{+} \mathrm{CD25}^{-}$(or fork-head box protein 3: $\mathrm{Foxp3}^{-}$) $\mathrm{CD4}^{+} \mathrm{T}$ cells, after treating a mouse model of arthritis with fingolimod (FTY720), and a pathogenic antigen may play a key role in the establishment of immune tolerance. In this study, we characterized a specific expanded $T$ cell subset in this population. Mice with glucose-6-phosphate isomerase peptide $\left(\right.$ GPI $\left._{325-339}\right)$-induced arthritis were treated with FTY720 (1 mg/kg, per os) and $\mathrm{GPI}_{325-339}(10 \mu \mathrm{g} / \mathrm{mouse}$, intravenously) for five days, starting from the onset of symptoms. The expanded GITR $^{+} \mathrm{CD25}^{-}$(or Foxp3 $\left.{ }^{-}\right) \mathrm{CD4}^{+} \mathrm{T}$ cell population and its cytokine production were examined using flow cytometry. Furthermore, time-dependent changes in T-bet and/or early growth response gene 2 (Egr-2) expression in this $T$ cell subset were examined. The density of $T$ cell immunoreceptors with immunoglobulin (Ig) and immunoreceptor tyrosine-based inhibition motif domains (TIGIT) ${ }^{+} \mathrm{CD}^{+} 9^{+}$cell subset in the GITR ${ }^{+}$Foxp3 $^{-} \mathrm{CD}^{+} \mathrm{T}$ cell population was significantly increased only in the combined treatment group, compared to that in the untreated and single-treatment groups. In the TIGIT $^{+} \mathrm{CD39}^{+} \mathrm{GITR}^{+} \mathrm{Foxp3}^{-} \mathrm{CD}^{+}{ }^{+} \mathrm{T}^{-}$ cell population, T-bet ${ }^{+}$Egr-2 ${ }^{+} /$T-bet $^{+}$Egr-2- ${ }^{-}$cell ratio increased in the latter stage of the treatment. Furthermore, this $T$ cell subset, which corresponded to a $T$ helper 1 (Th1) response, produced high levels of both interleukin (IL)-10 and interferon (IFN)- $\gamma$. In conclusion, expanded TIGIT $^{+}$CD39 $^{+}$GITR $^{+}$Foxp3 $^{-}$CD4 $^{+}$T $^{-10}$ cells shifted from an effector Th1 to IL-10-producing-suppressor T cell phenotype, which may promote an immune-tolerant state.
\end{abstract}

Key words fingolimod; immune tolerance; interleukin-10; T cell immunoreceptor with immunoglobulin and immunoreceptor tyrosine-based inhibition motif domain; glucocorticoid-induced tumor necrosis factor receptorfamily related gene/protein; pathogenic antigen

\section{INTRODUCTION}

Autoimmune diseases such as rheumatoid arthritis (RA), have repeated and chronic progressive courses of remission and relapse. Recent advances in the development of biological products have been reported to induce clinical remission; however, they do not treat the fundamental onset factors. Therefore, there is a need for developing a therapeutic method capable of inducing complete remission. In a previous study, we have shown that combined treatment of glucose-6-phosphate isomerase peptide $\left(\mathrm{GPI}_{325-339}\right)$-induced arthritis mouse model with fingolimod (FTY720) and pathogenic GPI $_{325-339}$ antigen significantly suppressed symptom progression. ${ }^{1)}$

Combined FTY720 and pathogenic antigen treatment effectively induced immune tolerance by mediating apoptosis, immunological unresponsiveness of pathogenic $\mathrm{T}$ cells, and immune suppression via regulatory $\mathrm{T}$ cells. ${ }^{2,3)}$ Further, relapse was efficiently suppressed after resensitization; only mild symptoms were observed, and the proportion of glucocorticoid-induced tumor necrosis factor receptor-family related gene/protein (GITR) ${ }^{+} \mathrm{CD} 25^{-}$(or fork-head box protein 3: Foxp $\left.3^{-}\right) \mathrm{CD}^{+} \mathrm{T}$ cells with high production of interleukin (IL)-10 increased with the combined treatment, which was associated with induction of immune tolerance. ${ }^{3)}$ In this study, we further delineated and characterized a specific high proliferating $\mathrm{T}$ cell subset in the $\mathrm{GITR}^{+} \mathrm{CD} 25^{-}$(or Foxp3 ${ }^{-}$) $\mathrm{CD}^{+} \mathrm{T}$ population responsible for these functions.

\section{MATERIALS AND METHODS}

Animals and Ethics Statement DBA/1J mice (Japan SLC, Japan) were bred under specific pathogen-free conditions. This study was performed according to a protocol approved by the Institutional Animal Care Committee of Setsunan University (Approval Nos. K16-16, K17-14). Throughout the experimental procedures, every effort was made to minimize the number of animals used and their suffering.

Induction of Arthritis and Treatment Protocol GPI $_{325-339}$-induced arthritis mouse model was established following the method of Iwanami et al. $\left.{ }^{4}\right)$ and was treated with FTY720 and/or GPI $_{325-339}$ as described previously. ${ }^{1-3)}$

Antibodies The following antibodies were purchased from BioLegend (U.S.A.): purified anti-mouse CD16/32 (93), allophycocyanin (APC)-Cy7-conjugated anti-mouse CD4 (GK1.5), brilliant violet 421 (BV421)-conjugated anti-mouse CD25 (PC61), fluorescein isothiocyanate (FITC) or phycoerythrin (PE)-Cy7-conjugated anti-mouse GITR (DTA-1), APC or $\mathrm{PE} /$ Dazzle-conjugated anti-mouse T cell immunoreceptor with immunoglobulin and immunoreceptor tyrosine-based inhibition motif domain (TIGIT) (1G9), PE-conjugated anti-mouse CD39 (Duha59), APC-conjugated anti-mouse IL-10 (JES516E3), PE-conjugated anti-mouse interferon (IFN)- $\gamma$ (XMG1.2) 
(A)

\section{GITR $^{+}$Foxp3 $^{-}$CD4 $^{+} \mathbf{T}$ cells gated}
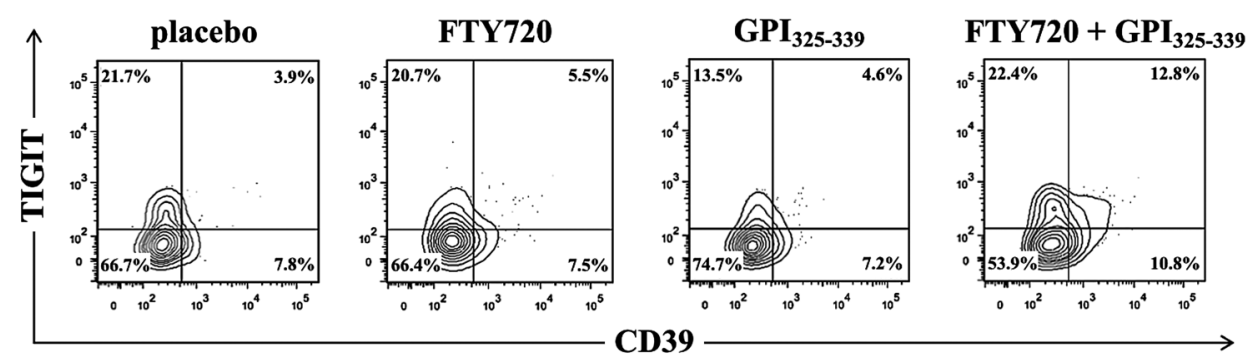

(B)

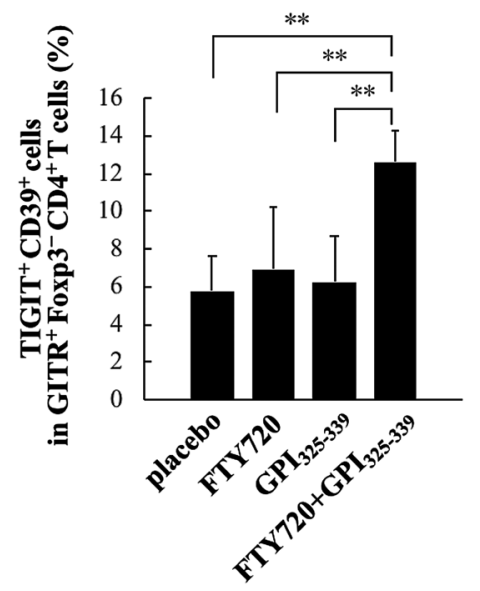

(C)

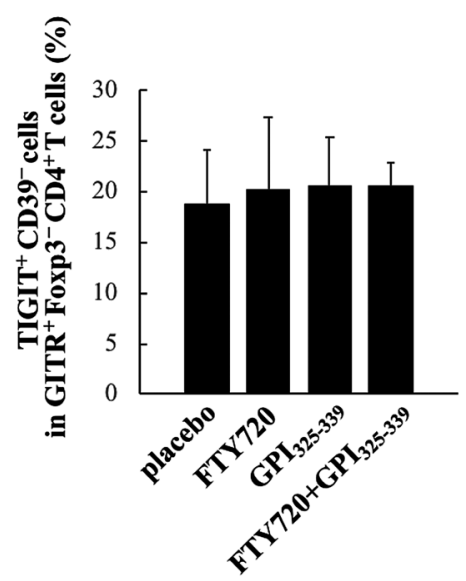

(D)

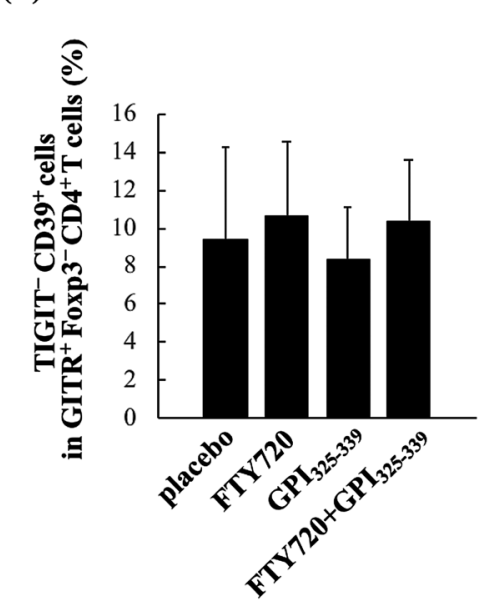

Fig. 1. Effect of Combined Treatment on the Percentage of TIGIT ${ }^{+} \mathrm{CD} 39^{+}$Cells in the GITR ${ }^{+}$Foxp $3^{-} \mathrm{CD} 4^{+}$T Cell Population

(A) Representative flow cytometry zebra plots of TIGIT and CD39 expression on gated $\mathrm{GITR}^{+} \mathrm{Foxp}^{-} \mathrm{CD} 4^{+} \mathrm{T}$ cells at the end of treatment. Bar graphs of the percent-

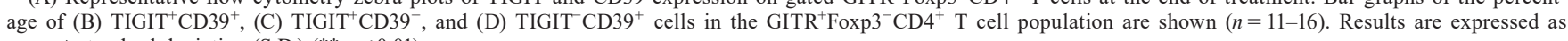
mean \pm standard deviation (S.D.) $(* * p<0.01)$.

and BV421-conjugated anti-mouse T-bet (4B10) monoclonal antibodies (mAbs). V500-conjugated anti-mouse CD4 mAb (RM4-5) was obtained from BD Biosciences (U.S.A.). FITCconjugated anti-mouse Foxp3 mAb (FJK-16s) was purchased from Thermo Fisher Scientific (eBiosciences; U.S.A.). APCconjugated anti-mouse early growth response gene 2 (Egr-2) mAb (REA869) was provided by Miltenyi Biotec (Germany).

Flow Cytometry Analysis and Cell Sorting Cells obtained from inguinal lymphoid nodes were filtered and incubated with $2 \%$ fetal bovine serum (FBS)-phosphate buffered saline (PBS) containing anti-mouse CD16/32 mAb (1:50) for $10 \mathrm{~min}$ at $4{ }^{\circ} \mathrm{C}$. Subsequently, the cells were stained with fluorescence-labeled mAbs $(1: 200)$ in $2 \%$ FBS-PBS for $30 \mathrm{~min}$ at $4{ }^{\circ} \mathrm{C}$ in the dark. Flow cytometry analysis and cell sorting were performed with BD FACS Aria II and BD FACS Aria Fusion (BD Biosciences).

To detect the expression of intracellular transcription factors, cells were fixed and permeabilized using the eBioscience $^{\mathrm{TM}}$ Foxp3/Transcription Factor Staining Buffer Set (Thermo Fisher Scientific) according to the instruction manual and stained with fluorescence-labeled anti-transcription factor mAbs $(1: 200)$ and then analyzed as above.

Intracellular cytokines were detected as follows. The cells were stimulated with complete RPMI 1640 medium $(10 \%$ FBS, penicillin (100 units $/ \mathrm{mL})$, streptomycin $(100 \mu \mathrm{g} / \mathrm{mL})$, and 2-mercaptoethanol $(50 \mu \mathrm{M}))$ containing Dynabeads ${ }^{\mathrm{TM}}$ Mouse T-Activator CD3/CD28 for $\mathrm{T}$ Cell Expansion and Activation (Thermo Fisher Scientific) and recombinant mouse IL-2
(rmIL-2, 50 units $/ \mathrm{mL}$, Miltenyi Biotec) for $3 \mathrm{~d}$ at $37^{\circ} \mathrm{C}$ under $5 \% \mathrm{CO}_{2}$ in 96 -well flat-bottom plates $\left(4-5 \times 10^{4}\right.$ cells $/ 200 \mu \mathrm{L} /$ well). Next, the cells were re-stimulated with complete medium containing eBioscience ${ }^{\mathrm{TM}}$ Cell Stimulation Cocktail (plus protein transport inhibitors) for $4-6 \mathrm{~h}$ at $37^{\circ} \mathrm{C}$ under $5 \% \mathrm{CO}_{2}$. The cells were then fixed and permeabilized as above, and were stained with fluorescence-labeled anti-cytokine mAbs $(1: 200)$ and then analyzed as above.

Statistical Analysis Statistical analyses were performed using Statcel 3 (OMS Publishing, Japan). The significance of the differences was determined using the Tukey-Kramer test for multiple comparison. $p<0.05$ was considered statistically significant.

\section{RESULTS}

Combined Treatment Increased the Number of Foxp3 $^{-} \mathrm{CD4}^{+}$T Cells Presenting TIGIT, CD39, and GITR Surface Markers It has been previously reported that GITR $^{+} \mathrm{CD}_{25} \mathrm{CD}^{+} \mathrm{T}$ cells suppress $\mathrm{T}$ cell proliferation. ${ }^{3)}$ Flow cytometry analysis (Figs. 1A, B) revealed a significant increase in the proportion of $\mathrm{TIGIT}^{+} \mathrm{CD} 39^{+}$cells in the GITR $^{+}$Foxp $^{-} \mathrm{CD}^{+} \mathrm{T}$ cell population in combination-treated mice compared to that in untreated mice or single-therapy treated mice. However, no difference was observed in the proportion of $\mathrm{TIGIT}^{+} \mathrm{CD}^{-}$and TIGIT $^{-} \mathrm{CD} 39^{+}$cells in GITR $^{+}$Foxp $3^{-} \mathrm{CD}^{+} \mathrm{T}$ cell population between the groups (Figs. 1A, C, D). Therefore, we concluded that the triple sur- 
(A)

TIGIT $^{+}$CD39 $^{+}$GITR $^{+}$Foxp3 $^{-}$CD4 $^{+}$T cells gated
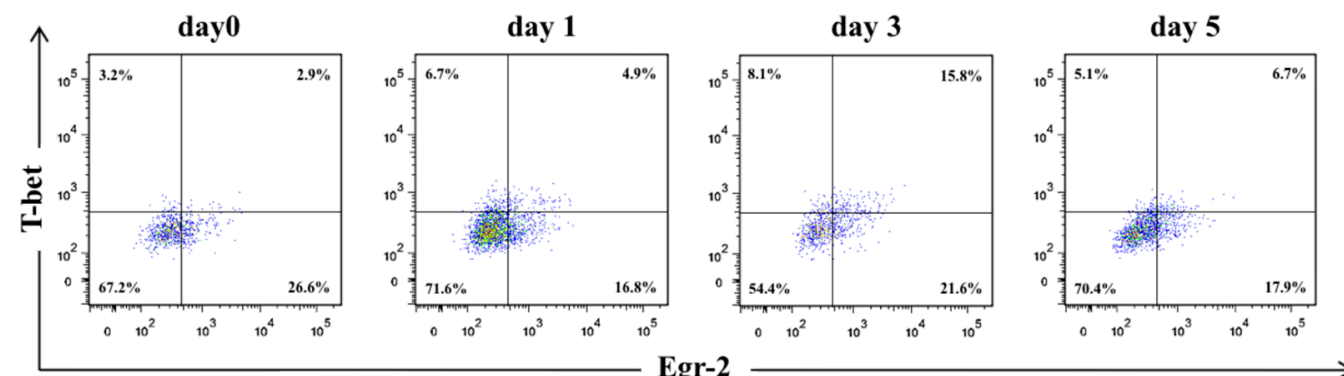

(B)

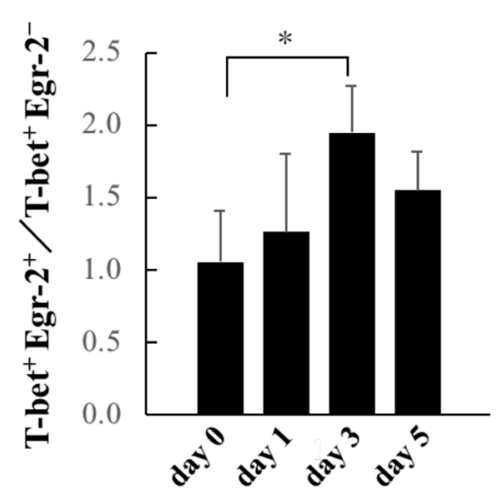

Fig. 2. Time-Course of T-bet ${ }^{+}$Egr- $2^{+} /$T-bet $^{+}$Egr- $2^{-}$Cell Ratio

(A) Representative flow cytometry dot plots of T-bet and Egr-2 expression on the gated $\mathrm{TIGIT}^{+} \mathrm{CD}_{3} 9^{+} \mathrm{GITR}^{+} \mathrm{Foxp}^{-} \mathrm{CD}^{+} \mathrm{T}^{-}$cell population at days $0,1,3$, and 5 after treatment. (B) Bar graphs of T-bet ${ }^{+}$Egr- $2^{+} / \mathrm{T}_{-}$bet ${ }^{+}$Egr- $2^{-}$cell ratio in the $\mathrm{TIGIT}^{+} \mathrm{CD} 39^{+} \mathrm{GITR}^{+}$Foxp3 ${ }^{-} \mathrm{CD}^{+}{ }^{+}$T cell population $(n=3-5)$. Results are expressed as mean \pm S.D. $(* p<0.05)$. (Color figure can be accessed in the online version.)

face expression of TIGIT, CD39, and GITR was increased in the $\mathrm{GITR}^{+} \mathrm{Foxp}^{-} \mathrm{CD}^{+} \mathrm{T}$ cell population by this combined treatment.

IL-10-Producing TIGIT $^{+}$CD39 $^{+}$GITR $^{+}$CD25 $^{-}$(or Foxp3 $\left.^{-}\right)_{\text {CD4 }^{+}} \mathrm{T}$ Cells Are Derived from a $\mathrm{T}$ Helper 1 (Th1) Cell Population It was previously reported that the $\mathrm{GITR}^{+} \mathrm{CD} 25^{-} \mathrm{CD} 4^{+} \mathrm{T}$ cell population expressed high levels of IL-10, IFN- $\gamma$, and IL-4 mRNA. ${ }^{5)}$ In this study, we hypothesized that the $\mathrm{T}$ cells with $\mathrm{Th} 1$ phenotype exist primarily in the $\mathrm{GITR}^{+} \mathrm{CD} 25^{-} \mathrm{CD} 4^{+} \mathrm{T}$ cell population.

By focusing on IFN- $\gamma$ - and IL-10-producing cells, the time-dependent changes in the number of T-bet and/or Egr-2 positive cells in the TIGIT $^{+} \mathrm{CD} 39^{+} \mathrm{GITR}^{+} \mathrm{Foxp}^{-} \mathrm{CD}^{+} \mathrm{T}$ cell population were examined in the combination-treated mice (Fig. 2A). In the $\mathrm{TIGIT}^{+} \mathrm{CD} 39^{+} \mathrm{GITR}^{+} \mathrm{Foxp}^{-} \mathrm{CD}^{+} \mathrm{T}$ cell population, the T-bet ${ }^{+}$Egr- $2^{+} / \mathrm{T}^{-}$bet ${ }^{+}$Egr- $2^{-}$cell ratio peaked at day three and slightly decreased on day five (Fig. 2), indicating that the expression of Egr-2 increased in T-bet ${ }^{+}$cells in the $\mathrm{TIGIT}^{+} \mathrm{CD} 9^{+} \mathrm{GITR}^{+} \mathrm{Foxp}^{-} \mathrm{CD}^{+} \mathrm{T}$ cell population following the combined treatment. The cytokine production profile of $\mathrm{TIGIT}^{+} \mathrm{CD} 39^{+} \mathrm{GITR}^{+} \mathrm{CD} 25^{-} \mathrm{CD}^{+}{ }^{+} \mathrm{T}$ cells was determined through flow cytometry (Fig. 3A). The IL-10 levels were high in all cell populations $\left(\mathrm{TIGIT}^{+} \mathrm{CD} 39^{+}, \mathrm{TIGIT}^{+} \mathrm{CD} 39^{-}\right.$, TIGIT $^{-} \mathrm{CD} 39^{+}$, and TIGIT $^{-} \mathrm{CD} 39^{-} \mathrm{GITR}^{+} \mathrm{CD} 25^{-} \mathrm{CD} 4^{+} \mathrm{T}$ cells), but were higher in TIGIT $^{+}$cell subsets $\left(\mathrm{TIGIT}^{+} \mathrm{CD} 39^{+}\right.$and TIGIT $^{+} \mathrm{CD}^{-} 9^{-} \mathrm{GITR}^{+} \mathrm{CD} 25^{-} \mathrm{CD}^{+}{ }^{+} \mathrm{T}$ cells) (Figs. 3A, B). The $\mathrm{TIGIT}^{+} \mathrm{CD} 39^{+} \mathrm{GITR}^{+} \mathrm{CD} 25^{-} \mathrm{CD} 4^{+} \mathrm{T}$ cell population was rich in both IFN- $\gamma$ and IL-10 double positive cells and IFN- $\gamma$ single positive cells (Figs. 3A, C, D).

\section{DISCUSSION}

The main goal of RA treatment is to induce clinical remission to allow the patient to maintain a long-term good QOL. In order to introduce complete remission of RA, it is necessary to create a conducive environment towards lymphocyte anergy. We initially hypothesized that $\mathrm{GITR}^{+} \mathrm{Foxp}^{-} \mathrm{CD}^{+} \mathrm{T}$ cells induced by the combined treatment might play a key role in establishing immune tolerance.

In this study, we demonstrated that the $\mathrm{GITR}^{+} \mathrm{Foxp} 3^{-} \mathrm{CD} 4^{+}$ $\mathrm{T}$ cell population was characterized by TIGIT and GITR marker expression, which increased after the combined treatment. It was reported that knockdown of TIGIT mRNA expression increased both T-bet and IFN- $\gamma$ mRNA levels, while significantly reducing IL-10 gene expression. ${ }^{6)}$ In this study, TIGIT-expressing cells secreted high levels of IL-10 in an anergic environment. Thus, expression of TIGIT may be important for the production of IL-10 and expression of TIGIT constituted a marker for identifying IL-10-producing cells.

The expanded TIGIT-expressing cells in combinationtreated mice also expressed CD39. CD39 which is coexpressed with CD73 (ecto-5'-nucleoside), is involved in degrading extracellular ATP into immune-suppressive adenosine. It was reported that CD39 contributed to the suppressive 
(A)
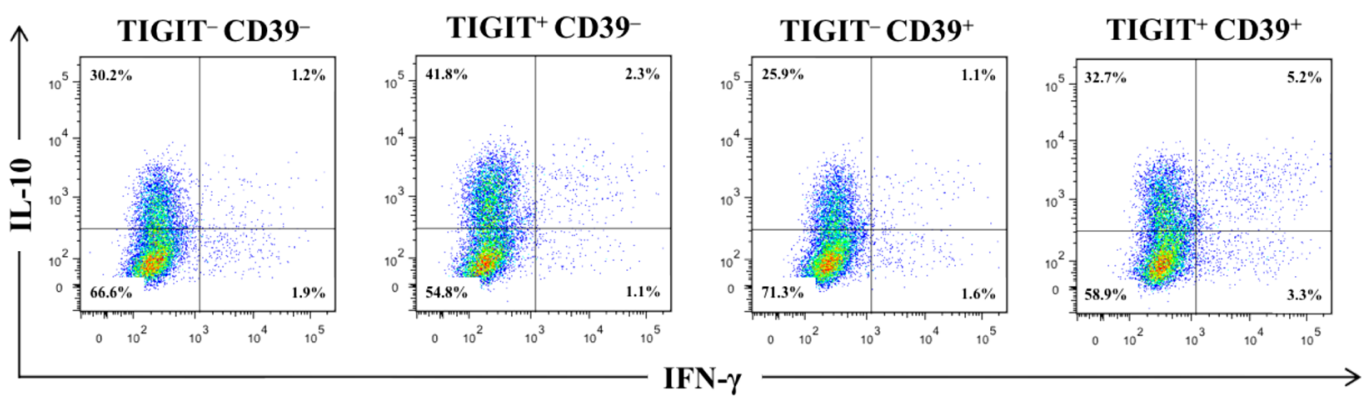

(B)

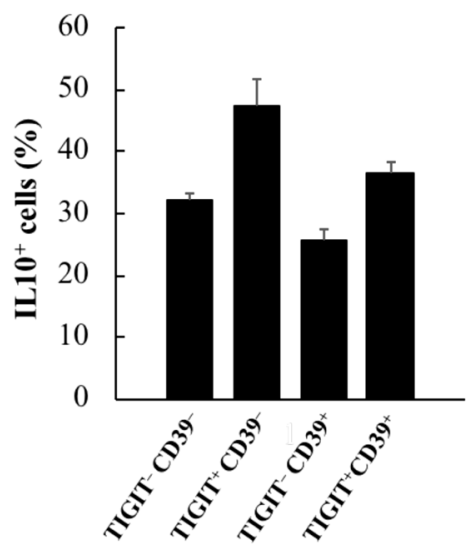

(C)

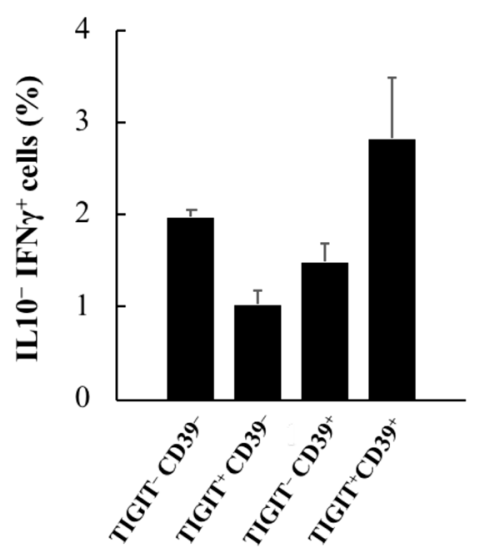

(D)

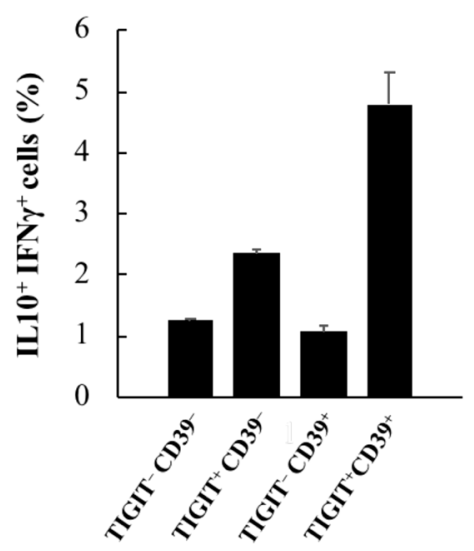

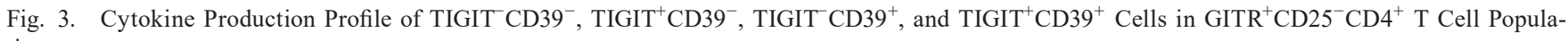
tion

TIGIT $^{-}$CD $39^{-}$, TIGIT $^{+}$CD $39^{-}$, TIGIT $^{-} \mathrm{CD} 39^{+}$, and $\mathrm{TIGIT}^{+} \mathrm{CD} 39^{+}$cells in $\mathrm{GITR}^{+} \mathrm{CD} 25^{-} \mathrm{CD}^{+} \mathrm{T}^{-}$cell population were sorted from inguinal lymph nodes, pooled from 8 or 12 mice, and intracellular cytokine staining was performed. (A) Representative dot plots of each cell population are shown. Bar graphs of the percentage of (B) IL-10 ${ }^{+}$ (C) IL-10 ${ }^{-}$IFN $-\gamma^{+}$, and (D) IL-10 ${ }^{+}$IFN- $\gamma^{+}$cells in each cell population are shown $(n=2)$. (Color figure can be accessed in the online version.)

activity of IL-10-producing T cells. ${ }^{7)}$ Thus, these results indicated that both TIGIT and CD39 were important molecules for suppressing the immune response by IL-10-producing cells.

T-bet, also known as T-box transcription factor TBX21, induces IFN- $\gamma$ production, and it is considered a 'master regulator' transcription factor for Th1 cell differentiation. Meanwhile, Egr-2 plays a key role in the negative regulation of $\mathrm{T}$ cell activation, and induces expression of IL-10 and lymphocyte activation gene 3 , which confers immunosuppressive activity to $\mathrm{CD}^{+} \mathrm{T}$ cells. In the early stage of combined treatment, the expression of T-bet was dominant, whereas that of Egr-2 became dominant towards the end of treatment. Similarly, previous in vitro studies have reported that the addition of IL-27 to Th1 conditions increases the proportion of IFN- $\gamma$ and IL-10 double positive cells, without altering the proportion of IFN- $\gamma$ positive cells. ${ }^{8}$ ) Therefore, it is postulated that a phenomenon exists in which effector $\mathrm{T}$ cells are directed to become IL-10-producing cells by specific cytokines, such as IL-27. Therefore, we considered that an anergic environment might be created by shifting from an effector Th1 to an IL10 -producing suppressive phenotype.

In conclusion, the number of $\mathrm{TIGIT}^{+} \mathrm{CD} 39^{+}$cells in the $\mathrm{GITR}^{+} \mathrm{CD} 25^{-}$(or Foxp3 ${ }^{-}$) $\mathrm{CD}^{+} \mathrm{T}$ cell population increased after the combined treatment and the expanded fraction of this cell population contained a high number of IL-10-producing cells with a Th1 phenotype. In future, the precise mechanism responsible for regulating the balance between IL-10-producing and IFN- $\gamma$-producing cells will be further characterized. We expect that this study will provide further insights on how to establish an anergic environment in an attempt to develop a therapy capable of inducing complete remission of RA.

Acknowledgments This work was supported by a Grantin-Aid for Young Scientists (B) (17K18263) and a Grant-in-Aid for Scientific Research (C) (19K08897), Japan Society for the Promotion of Science.

Conflict of Interest The authors declare no conflict of interest.

\section{REFERENCES}

1) Yoshida $Y$, Tsuji $T$, Watanabe S, Matsushima A, Matsushima Y, Banno R, Fujita T, Kohno T. Efficacy of combination treatment with fingolimod (FTY720) plus pathogenic autoantigen in a glucose6-phosphate isomerase peptide $\left(\mathrm{GPI}_{325-339}\right)$-induced arthritis mouse model. Biol. Pharm. Bull., 36, 1739-1746 (2013).

2) Yoshida Y, Mikami N, Matsushima Y, Otani F, Miyawaki M, Takatsuji M, Banno R, Tsuji T, Fujita T, Tsujikawa K, Kohno T. Functional mechanism(s) of the inhibition of disease progression by combination treatment with fingolimod plus pathogenic antigen in a glucose-6-phosphate isomerase peptide-induced arthritis mouse model. Biol. Pharm. Bull., 38, 1120-1125 (2015).

3) Yoshida Y, Mikami N, Matsushima Y, Miyawaki M, Endo $H$, Banno R, Tsuji T, Fujita T, Kohno T. Combination treatment with fingolimod and a pathogenic antigen prevents relapse of glucose6-phosphate isomerase peptide-induced arthritis. Immun. Inflamm. 
Dis., 4, 263-273 (2016).

4) Iwanami $K$, Matsumoto I, Tanaka $Y$, Inoue $A$, Goto D, Ito $S$, Tsutsumi A, Sumida T. Arthritogenic T cell epitope in glucose6-phosphate isomerase-induced arthritis. Arthritis Res. Ther., 10, R130 (2008).

5) Yoshida Y, Kohno T. Induction of immune tolerance by using fingolimod (FTY720), an immunosuppressive drug. Clinical Immunology \& Allergology, 71, 508-514 (2019).

6) Lozano E, Dominguez-Villar M, Kuchroo V, Hafler DA. The TIGIT/CD226 axis regulates human $\mathrm{T}$ cell function. J. Immunol.,
188, 3869-3875 (2012).

7) Mascanfroni ID, Takenaka MC, Yeste A, Patel B, Wu Y, Kenison JE, Siddiqui S, Basso AS, Otterbein LE, Pardoll DM, Pan F, Priel A, Clish CB, Robson SC, Quintana FJ. Metabolic control of type 1 regulatory T cell differentiation by AHR and HIF1- $\alpha$. Nat. Med., 21, 638-646 (2015)

8) Stumhofer JS, Silver JS, Laurence A, Porrett PM, Harris TH, Turka LA, Ernst M, Saris CJ, O'Shea JJ, Hunter CA. Interleukins 27 and 6 induce STAT3-mediated T cell production of interleukin 10. Nat. Immunol., 8, 1363-1371 (2007). 